\title{
PROPOSTAS DE ALTERNATIVAS PARA A REUTILIZAÇÃO DO PAPEL DESCARTADO PARA CONFECÇÃO DE TELHAS
}

\author{
L. B. P. FLORES ${ }^{1}$, M. D. C. de ALMEIDA $^{1}$ e N. de B. TAVARES ${ }^{1}$ \\ ${ }^{1}$ Universidade do Estado do Amapá \\ E-mail para contato: luanbpf@me.com
}

\begin{abstract}
RESUMO - O desenvolvimento de novos materiais a partir de materiais descartados tem sido um grande foco nas industrias de reciclagens de todo o mundo. Neste contexto, procuramos dar uma nova utilidade ao papel descartado além de que, dar um outro destino as fibras de coco, presentes de cocos (Cocos nucifera) descartados após o consumo de seu líquido. Sabe-se que, até então, as fibras de coco (presentes no mesocarpo do fruto) não são uteis as industrias atuais, descartando-os em lixões e produzindo uma série de impactos ambientais. Portanto, o objetivo deste trabalho foi estudar a possibilidade da confecção de telhas a partir da formação de um compósito constituído de papel A4 do tipo sulfit descartado e as fibras de coco, seguido também de um processo de impermeabilização com manta asfáltica, breu branco (Protium hepytaphylllum) e garrafas do tipo PET derretidas. Antes da formação do compósito, as fibras de cocos passaram por um processo de lixiviação com $\mathrm{NaOH}$ a $10 \%$, após isto, as fibras foram reduzidas a um comprimento aproximado de 1,5 cm. Em seguida, as fibras de coco juntamente com o papel foram triturados com o auxilio de um liquidificador, formando assim o compósito desejado, utilizou-se a proporção de $15 \%$ de fibras de coco e $85 \%$ de papel, salve exceção onde acrescentou-se 3\% de caulim para ensaio de flexão. Em seguida os corpos de prova foram formados através de moldes produzidos artesanalmente e impermeabilizados com as resinas em questão. Foram realizados ensaios de absorção de água (aumento de massa e inchamento de espessura) e ensaios de flexão (determinação do módulo de elasticidade e o módulo de ruptura). Os corpos de provas sem caulim e impermeabilizados com breu branco (Protium hepytaphylllum) possuíram resultados expressivos, com absorção de água de 142,41\%; inchamento de espessura de 4,51\%; módulo de elasticidade em 709,81 MPa e módulo de ruptura em 5,45 $\mathrm{MPa}$, sendo eles 5 vezes maiores do que os corpos de provas impermeabilizados com manta asfáltica, assumindo assim uma extrema possibilidade de confecção de telhas a partir de papel e fibras de coco, impermeabilizados com breu branco (Protium hepytaphylllum).
\end{abstract}

\section{INTRODUÇÃO}

Dentre vários materiais que compõe os resíduos como um todo, um deles e com grande abundância nos aterros sanitários e lixões, é o papel.

Segundo o PNSB 2008 (Pesquisa Nacional de Saneamento Básico) realizado pelo IBGE, 


\section{9 a 22 de outubro de 2014 \\ Florianópolis/SC}

mostrou que há a coleta de lixo em 100\% dos municípios brasileiros, mas a coleta seletiva ainda seria um método pouco praticado em muitos municípios do país. As regiões sul e sudeste, são as que mais se destacam neste tipo de coleta alcançando, respectivamente, $46 \%$ e 32,4\% dos municípios.

Na Região Norte a realidade de seletividade do lixo ainda é precária, e a destinação final dos resíduos a vazadouros de céu aberto (lixões) é bastante comum. Com maior saldo negativo, encontrase o Estado do Pará, com 94,4\% de descartes destinados a essas áreas, o Estado do Amapá, por sua vez, contém um grande volume de lixões, apenas 2 municípios (Macapá e Pedra Branca do Amapari) dispõe de aterro para disposição final de resíduos, e um índice, quase que zero, de coleta seletiva do lixo (IBGE, 2010).

Além deste, a lei $\mathrm{n}^{\circ}$ 12.305, de 2 de agosto de 2010, estabelece obrigatoriedade para a implantação da logística reversa e coleta seletiva e criação de aterros sanitários em todos os municípios brasileiros, sujeito a sansões o descumprimento desta.

\subsection{Problematização}

Dentre vários tipos de reaproveitamento, muitos são poucos explorados e processados para o papel, o mais utilizado é a reciclagem do papel, mas ainda pouco aderido a comunidade que utiliza tal produto.

Contribuindo a esta estimativa negativa, a coleta seletiva de papeis no Estado praticamente não existe, pois, mesmo que ocorra essa seletividade, em seu destino final, os tipos de resíduos são misturados, fazendo com que esta separação seja inútil.

Neste contexto, nem todo o papel residual é reutilizado para a reciclagem, ou seja, uma grande quantidade é deixada a degradação. No Estado, não há um processo de reciclagem contínuo e industrial do papel, este processo é presente apenas de forma artesanal atendendo apenas a necessidades de quem o utiliza.

Daí surge uma pergunta: será possível reutilizar o papel descartado para produzir produtos com valor agregado superior ao papel reciclado?

\subsection{Justificativa}

Outrora, apresenta-se metodologias que propõe um novo destino a estes tais papeis descartados, de modo que, além de contribuir para o reciclo de materiais (conservação de matéria prima), auxilia na obtenção de produtos com propriedades diferenciadas das comuns já conhecidas, estima-se que alguns materiais que necessitam de uma alta resistência possam ser substituídos por derivados do papel em função de suas propriedades de resistência mecânica.

Além disto, o projeto, indiretamente, apoia o Plano Nacional de Resíduos Sólidos (PNRS) reaproveitando os descartes deste material e diminuindo o impacto ambiental ao município onde será aplicado. 
Por fim, deve-se verificar as possíveis formações de polímeros, úteis para a humanidade. As telhas, utilizadas em construções civis se obtiverem propriedades melhores podem ter um tempo de vida maior do que as comumente utilizadas, substituindo as já utilizadas atualmente.

\section{OBJETIVOS}

\subsection{Geral}

Apresentar propostas de reutilização do papel descartado na construção de telhas.

\subsection{Específicos}

- Atenuar o reaproveitamento do papel para outros destinos, além da reciclagem;

- Realização de ensaios que comprovam a possibilidade de produção de telhas;

- Aplicação de diferentes resinas impermeabilizantes.

\section{PROCEDIMENTOS METODOLÓGICOS}

Os procedimentos metodológicos para produção de corpos de prova para testes foram divididos em três etapas: tratamento das fibras de coco; obtenção do compósito e aplicação de resinas impermeabilizantes.

\subsection{Tratamento das fibras do coco}

Nas fibras de coco, por ser um material similar a madeira, necessitou-se de um tratamento prévio com $\mathrm{NaOH}$. Este processo tem como finalidade a conservação das macromoléculas presentes no material, principalmente a lignina.

Do ponto de vista morfológico, a lignina é uma substância amorfa localizada na lamela média composta, bem como na parede secundária. Durante o desenvolvimento das células, a lignina é incorporada como o último componente na parede, interpenetrando as fibrilas e assim fortalecendo, enrijecendo as paredes celulares. (Klock, 2005).

Após a separação do mesocarpo do fruto, as fibras foram imergidas em solução de $\mathrm{NaOH} 10 \%$ e permaneceu sob agitação constante durante 30 (trinta) minutos. Em seguida, o material fora neutralizado com água corrente até que seu pH atingisse o valor de 7 (sete), medido com o auxílio de papeis universais macherey nagel $\mathrm{pH}$-Fix 0-14.

O método adotado para regulagem do pH para neutro, foi da imersão e agitação das fibras de coco em água corrente, fazendo com que a concentração de $\mathrm{NaOH}$ diminuísse sobre as fibras. 


\section{9 a 22 de outubro de 2014 \\ Florianópolis/SC}

Por fim, levou-se o material a estufa de circulação e permaneceu a $70^{\circ} \mathrm{C}$ até secagem completa.

\subsection{Preparação da polpa de papel e formação do material}

Nesta fase do processo, trata-se da união do papel com a fibra de coco já tratadas. As fibras após secas, sofreram redução em seu comprimento para aproximadamente $1,5 \mathrm{~cm}$.

Segundo Passos, (2005), a mistura de papel e fibras de coco que obtiveram melhores resultados nos ensaios mecânicos e na absorção de água foram os preparados com $85 \%$ de papel e $15 \%$ de fibras de coco. Desta forma, adotou-se esta fração, assim, para a produção de $1,3812 \mathrm{~kg}$ de compósito, $207,41 \mathrm{~g}$ foi de fibras de coco e os 1175,37 $\mathrm{g}$ restantes a massa da polpa de papel foram utilizadas.

Continuamente, utilizou-se papel oriundo de revistas e papeis A4 do tipo sulfit. Os papéis foram coletados nos diversos setores da Universidade do Estado do Amapá (UEAP) e sofreram um processo de pré tratamento. Nesta etapa, seguiu-se as seguintes operações: trituração e formação da polpa a partir da maceração com água em liquidificador.

A trituração é necessária para maior interação das macro moléculas presentes no papel, principalmente a celulose, e uma suposta homogeneização do material em estudo.

A Celulose, é o componente majoritário, perfazendo aproximadamente a metade das madeiras tanto de coníferas, como de folhosas. Pode ser brevemente caracterizada como um polímero linear de alto peso molecular, constituído exclusivamente de $\beta$-D-glucose. (Klock, 2005)

Assim, para início da produção da polpa de papel, o material foi cortado, com o auxílio de uma máquina de cortar papel, pesado a quantidade de 391,79 gramas de papel e triturado com o auxílio de um liquidificador Wallita de 1,5 L, formando a polpa.

Em pré-testes, na formação material houve grandes dificuldades em reposicionar as fibras de coco no interior da polpa, visto que por ser um material de geometria longitudinal ficavam sempre se agregando e formando aglomerados de fibras impedindo a homogeneização do compósito. Em processos finais, onde as fibras foram reduzidas, o compósito apresentou-se mais homogêneo, com suas fibras bem distribuídas, garantindo assim a proporção de $15 \%$ desejado, em todas as partes do compósito.

Juntamente com a inserção do papel ao liquidificador, foi misturada, 69,13 gramas de fibras de coco para formar a mistura desejada. Este material tem por finalidade uma maior resistência mecânica do produto final (telha).

Após o término da homogeneização, juntamente com a polpa formada, foi adicionado água até que a mistura atingisse 15 litros e em seguida o material foi submetido a um processo de filtração. Telas construídas medido $55 \times 45 \mathrm{~cm}$ foram responsáveis por tal processo. Vale ressaltar que esta filtração não retirou toda a água presente no compósito, mas sim grande parte. Para isto, a tela de filtração, com a mistura retida, foi levada a estufa de secagem NOVA ÉTICA e por lá permaneceu durante 22 horas. 
Para a filtração, cada tela suportou 460,93 g de compósito produzido, dando um total de 1382,79 g de compósito utilizados para produção de corpos de provas para ensaios e testes (três telas foram utilizadas).

\subsection{Ensaio de absorção de água}

O ensaio de absorção de água, que contempla o aumento de massa e inchamento de espessura, foi executado de acordo com a norma ASTM D 1037-99. Antes da imersão, os corpos de provas foram marcados ao centro de cada aresta que o compõe, as peças foram submergidas em água destilada de nível aproximado a $2,5 \mathrm{~cm}$ e permaneceram submergidos por 24 horas, sua massa e sua espessura foram medidas antes e após o fim do processo.

Para este ensaio, foram produzidos 4 corpos de provas para cada tipo de impermeabilizante, sendo eles o breu branco (Protium hepytaphylllum), manta asfáltica em solvente e resinas de garrafas do tipo PET derretidas, além de, 8 corpos de provas sem impermeabilização, dando um total de 20 corpos de provas para tal ensaio.

\subsection{Ensaio de flexão em 3 pontos}

O ensaio de flexão em 3 pontos foi executado com o auxílio do equipamento para ensaios da EMIC DL 30000, com largura útil de $650 \mathrm{~mm}$. Os apoios foram separados a uma distância de $9 \mathrm{~cm}$. Com este ensaio, determinou-se a módulo de ruptura (MOR) e o módulo de elasticidade (MOE) do material.

\section{RESULTADOS E DISCUSSÕES}

\subsection{Tratamento das fibras de coco}

As micrografias obtidas por Florentino, et al, (2011) realizadas por um microscópio eletrônico de varredura pode avaliar os aspectos morfológicos de fibras de coco tratadas com $\mathrm{NaOH} 10 \%$ e in natura, os resultados concluíram que as fibras tratadas possuíam maior resistência a tração, resultado explicado pela remoção de extrativos e ceras, no qual favoreceu a interação entre fibra/matriz.

Tal tratamento foi realizado a fim de obter resultados maiores quanto a resistência mecânica do material, Passos, (2005), realizou ensaios com fibras de coco in natura obtendo resultados satisfatórios, então a utilização de fibras de coco tratadas expõe resultados superiores.

\subsection{Formação da mistura}

O material desejado possuía a proporção de $85 \%$ de papel e $15 \%$ de fibras de coco, onde segundo Passos, (2005) adotou como a melhor proporção pra tal compósito.

A adição de fibras de coco tratadas com $\mathrm{NaOH}$ tem a finalidade de aumentar a resistência a tração do compósito, pois os extrativos e ceras são retirados da superfície do material, aumentando 
assim a interação da fibra/matriz do papel com as fibras.

\subsection{Impermeabilização dos corpos de provas}

A impermeabilização dos corpos de provas tem por finalidade a rejeição de água pelo compósito, além do aumento na resistência mecânica do material.

Os corpos de provas resinados com garrafas do tipo PET foram descartados, visto que não foi possível a aplicação da resina no compósito, pois a temperatura de fusão do polímero se encontra na faixa de $230^{\circ} \mathrm{C}$, superior a temperatura de combustão do compósito de $200^{\circ} \mathrm{C}$, além de que o PET possui uma acelerada capacidade de solidificação, a ponto de se solidificar antes de ser aplicado ao compósito.

Aplicou-se duas camadas de manta asfáltica em solvente em decorrência a instruções obtidas no rótulo da embalagem do produto. Nas demais resinas não foram necessárias mais de uma camada, visto que o comportamento das mesmas fora diferente da manta asfáltica.

Os corpos de provas resinados com asfalto em solvente apresentou um bom desempenho, visto que a resina impregnou-se ao compósito, em contra partida, o breu branco (Protium hepytaphylllum) após aplicado, criou uma camada externa, dividindo o compósito do meio externo.

\subsection{Absorção de água}

Os resultados dos ensaios foram submetidos a testes de rejeição de valores dispersos (teste de dixon e teste de grubbs). As médias dos resultados das análises constam na tabela 2.

Tabela 2 - Resultados do ensaio de Absorção de Água.

\section{Corpos de Prova}

$\begin{array}{cccc}\text { Resina Impermeabilizante } & \text { Breu Branco (\%) } & \text { Manta asfáltica (\% } & \text { Sem resina (\%) } \\ \text { Aumento de Massa } & 142,41 & 144,35 & 289,58 \\ \text { Aumento de Espessura } & 4,51 & 11,59 & 3,47\end{array}$

De acordo com os dados obtidos, a impermeabilização com breu branco (Protium hepytaphylllum) foi a mais adequada para absorção de água, visto que o aumento de massa e da espessura foi menor que a impermeabilização com manta asfáltica.

Por análise, o aumento da espessura dos corpos de provas impermeabilizados com breu branco (Protium hepytaphylllum) serem maiores do que os corpos de provas sem resinas, dar-se pela presença de uma substância a mais para a retenção da água (o breu), visto que o material não resinado não possuía isto.

A baixa porcentagem em aumento de massa dos corpos de provas impermeabilizados com breu 
branco (Protium hepytaphylllum), é justificado pela forma como se comportava a resina no corpo de prova. Ao contrário dos demais corpos de provas, o breu criou uma camada externa "protegendo" o compósito de papel e fibra de coco com o meio externo, evitando assim grande parte da entrada de água.

Em termos de estrutura, os corpos de provas impermeabilizados com o breu, mantiveram suas estruturas intactas após o término do ensaio, enquanto os demais corpos de provas racharam, quebrando-se em vários pedaços.

\subsection{Flexão em 3 pontos}

Os resultados dos ensaios foram submetidos a testes de rejeição de valores dispersos (teste de dixon e teste de grubbs). As médias dos resultados das análises constam na tabela 3 (corpos de provas sem caulim) e tabela 4 (corpos de provas com caulim).

Tabela 3: Resultados do ensaio de flexão em 3 pontos em corpos de provas sem caulim.

\begin{tabular}{ccc}
\hline & \multicolumn{2}{c}{ Corpos de Prova sem caulim } \\
\cline { 2 - 3 } Resina Impermeabilizante & Breu Branco (MPa) & Manta asfáltica (MPa) \\
Módulo de Ruptura & 5,45 & 1,46 \\
Módulo de Elasticidade & 709,81 & 71,98 \\
\hline
\end{tabular}

Tabela 4: Resultados do ensaio de flexão em 3 pontos em corpos de provas com caulim.

\begin{tabular}{ccc}
\hline & \multicolumn{2}{c}{ Corpos de Prova com caulim } \\
\cline { 2 - 3 } Resina Impermeabilizante & Breu Branco (MPa) & Manta asfáltica (MPa) \\
Módulo de Ruptura & 4,28 & 1,46 \\
Módulo de Elasticidade & 469,43 & 45,87 \\
\hline
\end{tabular}

De acordo com os dados obtidos, os corpos de provas sem caulim resinados com breu branco (Protium hepytaphylllum) obtiveram resultados de boa expressão nesta metodologia de ensaio, sendo eles aproximadamente 5 vezes maior do que os corpos de provas resinados com manta asfáltica.

A diferença entre os corpos de prova neste ensaio, é devido a "casca" criada pelo breu externamente ao corpo de prova, tal estrutura concebeu maior resistência a flexão ao material.

A adição de caulim prejudicou o compósito nos ensaios mecânicos, devido a uma propriedade dessa substância de que, após seco, possui um aspecto de giz, dificultando a interação das moléculas de celulose e lignina presentes no do papel e das fibras de coco. 


\section{CONCLUSÃO}

A metodologia de produção dos compósitos foi bastante significativa, mas a mesma poderia ter sido mais expressiva, de forma a possuir equipamentos em base industrial, como refinadores, moinhos e classificadores.

Infelizmente, por falta de infra estrutura e por aparelhos laboratoriais, não foi possível obter uma telha conforme objetivo do projeto, muito menos realizar ensaios sobre a mesma. Entretanto, os ensaios adotados nos corpos de provas obtidos no processo foram de grande relevância para a possibilidade de produção de coberturas.

Das resinas impermeabilizantes aplicadas, o breu branco (Protium hepytaphylllum) obteve maior destaque, expressando resultados em até 5 vezes maiores aos corpos de provas resinados com manta asfáltica, entretanto, a aplicação não fora a melhor adotada, pois foi formado apenas uma camada externa de impermeabilizante, é possível que a impermeabilização por imersão proporcione ainda mais benefícios ao material em questão.

Por fim, compreende-se que pelos resultados obtidos, uma telha composta de papel e fibras de coco, com proporções aproximadas adotadas no trabalho e resinadas com breu, teriam sua correta funcionalidade.

\section{REFERÊNCIAS}

ASTM D 1037-91. American Society for Testing Materials. Standard methods of evaluating the properties of wood-base fiber and particle panel materials. Philadelphia, 1999.

Instituto Brasileiro de Geografia e Estatística - IBGE. Pesquisa nacional de saneamento básico 2008. IBGE: Rio de Janeiro. 2010.

KLOCK, Umberto. et al. Química da madeira. 3 Ed. revisada. Curitiba. 2005.

PASSOS, Paulo. Destinação sustentável de cascas de coco (Cocos Nucifera) verde: obtenção de telhas e chapas de partículas. Tese de mestrado. UFRJ:Rio de Janeiro. 2005.

SILVA, Luiz Inácio Lula da; et al. Lei $\mathrm{n}^{\circ}$ 12.305, de 02 de agosto de 2010. Disponível em: < http://www.planalto.gov.br/ccivil_03/_ato2007-2010/2010/lei/112305.htm> acesso em: 04 de fevereiro de 2012, ás $01 \mathrm{hr} 17 \mathrm{~min}$.

FLORENTINO, Wagner Martins; BRANDÃO, Amanda; MILÉO, Patrícia Câmara; GOULART, Shane Aparecida Soares; MULINARI, Daniella Regina. Biocompósitos de Poliuretano reforçados com Fibras de Coco Verde. Cadernos UniFOA. Volta Redonda, Ano VI, n. 17, dezembro 2011. 